\title{
Factors influencing probiotics recommendation among pediatricians in Indonesia
}

\author{
Ray Wagiu Basrowi ${ }^{1}$, Deni Krisnamurti ${ }^{1}$, Yulianti Wibowo ${ }^{1}$ and Yvan Vandenplas ${ }^{2 *}$ \\ ${ }^{1}$ Nestle Nutrition Institute, Indonesia \\ ${ }^{2}$ KidZ Health Castle, UZ Brussel, Vrije Universiteit Brussel, Brussels, Belgium
}

\begin{abstract}
Purpose: To help pediatrician utilize probiotic use correctly, it is important for them to keep updated about new knowledge through various sources and methods. This study aimed to evaluate clinical behavior and factors influencing pediatricians to consider probiotic recommendation in infants and toddlers patients.

Patients and methods: A cross-sectional study conducted to 99 pediatricians attended Probiotic Summit in Jakarta on July 2018. Data collection aimed to gather characteristics of the subject's age, employment and affiliation status and years having pediatric practice through self-administered questionnaire. The current knowledge, clinical behavior and others factors influencing pediatricians to consider recommendation collected using modified 12-items questionnaire by Legare et al, 2014

Results: about 99 pediatricians participated in the study; of which 58 subjects worked in private hospital and 41 subjects were government hospital-based pediatricians. Majority of subjects were aged between $40-60$ years old and $71 \%$ had been worked in pediatric clinical practice for more than 10 years. Almost all of subjects showed confident with scientific evidences (99\%) and agreement on ethical importance of probiotic in infants and toddlers (98\%), which was reflected to their positive prescribing consideration. From self-assurance perspective, $97 \%$ of subjects convinced with probiotic usage in infants and toddler, and hence consider to prescribe probiotic to their patients [OR (CI95\%):0.50 (0.12-1.99); $\mathrm{P}=0.02)$. The multivariate analysis comparing the outcome variables to subject's consideration to prescribe found that knowledge $(\mathrm{P}=0.05)$, ethical consideration $(\mathrm{P}<0.001)$, self-assurance $(\mathrm{P}<0.001)$, clinical behavior $(\mathrm{P}<0.001)$, and attitude $(\mathrm{P}<0.001)$ were factors that strongly associated with subject's consideration to prescribing probiotic to their patients.
\end{abstract}

Conclusion: Knowledge, scientific evidences and ethical point of view were key factors influencing pediatricians to recommend probiotic to their patients.

\section{Introduction}

A balanced bacterial gut colonization in early life has a long-term influence on the health status because a matures the gut mucosal barrier, contributes to a healthy development of the immune system and prevents infections. The gut microbiota development in breast- and formula-fed infants differs, because of the differences in composition between both feeding. While breastmilk contains a large amount of oligosaccharides and some probiotics, standard non-supplemented infant formula does not [1]. Manipulation of the gut microbial composition in formula-fed infants through pre- and probiotic supplementation is considered to support health [2-5].

The Food and Agriculture Organization (FAO) of the United Nations and the World Health Organization (WHO) define a probiotic as "live micro-organisms which, when administered in adequate amounts, confer a health benefit on the host [6]. Pooled data on studies of probiotic-supplemented infant or follow-on formula shows that supplementation of infant formula with Bifidobacterium (B.) lactis (single or in combination) is associated with a reduced risk of nonspecific gastrointestinal infections in children $[7,8]$.

Therefore, it is important to update health care professionals such as pediatricians about the evolution of the knowledge on the effects of probiotic administration during early life through various sources and methods such as continuous medical education (CME), lectures, workshops, case-based learning, clinical experiences, preceptorships, and even direct information via interaction with representatives from nutrition companies $[9,10]$. CME interventions have limited impact [11].

Studies show that the prescribing pattern of physicians strongly depend on a series complex factors, including personal motivation as well as external factors such as requests from patients [12]. Doctors' prescription patterns are not standardized but are dynamic and individual [13-15].

This study aimed to evaluate the attitude of pediatricians to recommend probiotics, specifically to infants and toddlers.

\section{Material and methods}

Data were collected from 99 pediatricians attending a Probiotic Summit in Jakarta in July 2018. Data collection aimed to gather information on the age, employment and affiliation status, and years in pediatric practice through a questionnaire.

${ }^{\star}$ Correspondence to: Yvan Vandenplas, $\mathrm{MD}, \mathrm{PhD}, \mathrm{KidZ}$ health castle, UZ Brussel, laarbeeklaan 101, 1090 Brussels, Belgium, Tel: +3224775794; Fax: +324775783; E-mail: yvan.vandenplas@uzbrussel.be

Key words: pediatricians, probiotic recommendation, prescribe, infants, toddlers

Received: July 23, 2019; Accepted: September 02, 2019; Published: September 05,2019 
The current knowledge, clinical behavior and others factors influencing pediatricians to consider prescription of probiotics were collected using a modified 12-items questionnaire which was developed by Legare [16]. Knowledge of probiotic is all information that a person possesses or accrues after education, obtain from series of self-administered questionnaire from probiotic lecture. Attitude and clinical behavior is the way in which a person responds to a certain set of conditions, related to the use of probiotic in infants and toddlers. Selfassurance measures how convinced the pediatrician is regarding the effects of probiotics, while confidence of scientific evidence indicates the belief of pediatricians on the clinical data and scientific information [17].

All of the influencing factors were indicated through the adapted questionnaire. A chi-square test was used to analyze cross-tabulated data for bivariate analysis and general linear model for multivariate analysis, using SPSS version 20, with all outcome variables taken at the $5 \%$ significance level $(\mathrm{P}<0.05)$ and within $95 \%$ confidence interval. The study protocol approved by ethics committee of Faculty of Medicine Universitas Indonesia, letter number KET-296/UN2.F1/ETIK/ PPM.00.02/2019.

\section{Results}

A total of 99 pediatricians participated in this research; 58 worked in a private hospital and 41 were governmental hospital-based pediatricians (Table 1).

Table 2 shows that almost all participants perceived to be confident with scientific evidence (99\%) and agreed on the ethical importance of recommending probiotics in infants and toddlers (98\%). From the self-assurance perspective, $97 \%$ of the subjects were convinced of the benefits of probiotic use in infants and toddler, and hence consider prescribing probiotics to their patients [OR (CI95\%):0.50 (0.12-1.99); $\mathrm{P}=0.02)$. Hovewer, about half of the participants said to consider to not prescribe probiotics if peers informed them about negative outcome.

Table 3 shows the outcome of a multivariate analysis of different variables regarding when to prescribe probiotics: knowledge $(\mathrm{P}=0.05)$, ethical consideration $(\mathrm{P}<0.001)$, self-assurance $(\mathrm{P}<0.001)$, clinical behavior $(\mathrm{P}<0.001)$, and attitude $(\mathrm{P}<0.001)$ were associated with the consideration to prescribe probiotics.

Table 1. Demographic and occupational characteristic of subject

\begin{tabular}{|l|c|}
\hline Variable & $\begin{array}{r}\mathbf{n}(\mathbf{\%}) \\
\mathbf{n}=\mathbf{9 9}\end{array}$ \\
\hline Gender & $43(43)$ \\
\hline Male & $56(57)$ \\
\hline Female & \\
\hline Age (years old) & $4(4)$ \\
\hline$>60$ & $25(25)$ \\
\hline $50-60$ & $51(52)$ \\
\hline $40-50$ & $19(19)$ \\
\hline $30-40$ & $8(8)$ \\
\hline Duration of clinical practice (years) & $21(21)$ \\
\hline$<5$ & $37(38)$ \\
\hline $5-10$ & $33(33)$ \\
\hline $10-15$ & \\
\hline$>15$ & $41(41)$ \\
\hline Affiliation & $58(59)$ \\
\hline Government hospital & \\
\hline Private hospital/clinic & \\
\hline
\end{tabular}

Table 2. Cross tabulation of factors influencing prescribing among pediatricians

\begin{tabular}{|c|c|c|c|c|}
\hline Variable & $\begin{array}{c}\text { Consider to } \\
\text { prescribe } \\
\mathrm{n}(\%)\end{array}$ & $\begin{array}{c}\text { Not consider to } \\
\text { prescribe } \\
\mathrm{n}(\%)\end{array}$ & OR (CI95\%) & $\mathbf{P}$ \\
\hline \multicolumn{5}{|l|}{ Self-assurance } \\
\hline Convinced & $96(97)$ & $1(1)$ & $0.50(0.12-1.99)$ & 0.02 \\
\hline Not convinced & $1(1)$ & $1(1)$ & - & - \\
\hline \multicolumn{5}{|c|}{ Confident with the scientific evidences } \\
\hline Yes & $98(99)$ & $0(0)$ & - & 0.01 \\
\hline No & $1(1)$ & $0(0)$ & - & - \\
\hline \multicolumn{5}{|c|}{ Practicality of probiotic usage } \\
\hline Practical & $84(85)$ & $1(1)$ & - & 0.85 \\
\hline Not practical & $14(14)$ & $0(0)$ & - & - \\
\hline \multicolumn{5}{|l|}{ Ethical } \\
\hline Agree & $97(98)$ & $0(0)$ & - & 0.02 \\
\hline Not agree & $1(1)$ & $1(0)$ & - & - \\
\hline \multicolumn{5}{|l|}{ Peer Influence } \\
\hline Positive & $45(45)$ & $1(1)$ & $1.01(0.98-1.06)$ & 0.53 \\
\hline Negative & $1(1)$ & $52(53)$ & - & - \\
\hline \multicolumn{5}{|l|}{ Knowledge } \\
\hline Good $(\geq 80)$ & $38(38)$ & $1(1)$ & $0.97(0.92-1.03)$ & 0.39 \\
\hline Average $(<80)$ & $59(60)$ & $1(1)$ & - & - \\
\hline \multicolumn{5}{|l|}{ Attitude } \\
\hline Positive & $97(98)$ & $1(1)$ & - & 0.02 \\
\hline Negative & $1(1)$ & $0(0)$ & - & - \\
\hline \multicolumn{5}{|l|}{ Behavior } \\
\hline Positive & $92(92)$ & $0(0)$ & - & 0.07 \\
\hline Negative & $6(7)$ & $1(1)$ & - & - \\
\hline
\end{tabular}

Table 3. Logistic multivariate regression model on factors associated to subjects consideration to prescribe probiotic

\begin{tabular}{|c|c|c|c|}
\hline Variables & OR (CI95\%) & R2 & P \\
\hline Peer influence & $1.00(0.04-1.99)$ & 0.01 & 0.35 \\
\hline Knowledge & $1.00(0.19-1.80)$ & 0.02 & 0.05 \\
\hline Ethical consideration & $0.99(0.97-1.01)$ & 0.49 & $<0.001$ \\
\hline Self-assurance & $0.99(0.97-1.00)$ & 1.00 & $<0.001$ \\
\hline Practicality & $0.14(0.07-0.21)$ & 0.10 & 0.68 \\
\hline Clinical behavior & $0.95(0.91-0.99)$ & 0.15 & $<0.001$ \\
\hline Attitude & $0.99(0.97-1.01)$ & 0.49 & $<0.001$ \\
\hline
\end{tabular}

\section{Discussion}

This study reports that knowledge, self-assurance and scientific evidences on the benefits of probiotics are key factors for pediatricians before considering prescribing infant formula, growing up milk and pediatric supplements containing probiotics. Continuous education programs contribute significantly to prescription attitudes of physicians [18].

Medical education, and in postgraduate education particularly on efficacy and safety of treatment, have been shown to be major determinants in prescription attitudes of health care professionals [19]. Knowledge and thus adherence of standard clinical guidelines on treatment which include the rational use of drugs, pharmacovigilance, evidence-based medicine, and pharmaco-economics are essential to improve the prescribing patterns among general practitioners $[20,21]$.

Doctors will adapt their prescribing decision-making process if this is supported by evidence that includes both regulatory and clinical information as well as the analysis of clinical practice data [22]. Availability of clinical data demonstrating the therapeutic efficacy increases confidence among prescribers [22,23]. This study might explain why participants in this study to uphold the evidence-based concept is also reported for prescribing probiotics. 
The importance of influence by peers was also reported in this study. Even though the difference was not statistically significant, the high percentage of subjects who would not consider prescribing probiotics related to negative peer influence. Peers share knowledge among colleagues with the aim to deliver specific guidance on appropriate prescribing attitudes [22]. A Study by King et al. showed that peer influence and physician peer networks acted as alternative source of information about clinically advantageous medications when restrictions on pharmaceutical detailing existed, hence factors to determine prescribing pattern [24].

In that context, networks of peers do influence physician prescribing behavior, making social network-based contacts a promising substitute for marketing [25]. Some health care providers have even expressed the view that stronger directions and guidelines from authority organizations would be welcomed to improve their prescribing attitudes [19]. The importance of the opinion of peers was also highlighted in this study.

A reviewed by Majid showed that prescribing decision by physicians is the result of a multitude-intertwined factors. There were 33 factors identified in the review. Physicians' personal attribute was one main important factor, which include clinical experience, specialty, continuous professional development and practice decision. The information source used by physicians have an important role in altering their prescribing decision. Although medical reference books and scientific literatures have a large theoretical importance, colleagues and scientific meeting might useful as additional source information used to prescribe new medicine [26].

To the best of our knowledge, this is the first study to evaluate factors which influencing pediatricians to recommend probiotics in Indonesia. Therefore, the results of this study can be considered as novel findings to better understand the pattern of prescription, particularly toward probiotic products.

However, we also acknowledged limitation of this study is the cross-sectional design that cannot summarize any causality and the subjects are pediatrician who attend the symposium that may not representative for Indonesia. Secondly, there might be another factor influence pediatrician behavior in prescribing probiotics that not included in this study, which shown by lower value of $\mathrm{R}$ in multivariate analysis.

\section{Conclusion}

Knowledge and scientific evidences are key factors influencing pediatricians to recommend probiotic to their patience. The influence from peer and colleagues were also critical, as it mainly because it was reflecting the collective view of which product should be prescribed and which should not, including probiotic. Further studies and regular education need to be continued for pediatricians to update with the evolving scientific knowledge.

\section{Disclosure}

RWB, DK and YW are employee of Nestle Nutrition Institute.

\section{References}

1. Vandenplas Y, De Greef E, Veereman G (2014) Prebiotics in infant formula. Gut Microbes 5: 681-687. [Crossref]

2. Bertelsen RJ, Jensen ET, Ringel-Kulka T (2016) Use of probiotics and prebiotics in infant feeding. Best Pract Res Clin Gastroenterol 30: 39-48. [Crossref]
3. Soto A, Martín V, Jiménez E, Mader I, Rodríguez JM, et al. (2014) Lactobacilli and bifidobacteria in human breast milk: influence of antibiotherapy and other host and clinical factors. J Pediatr Gastroenterol Nutr 59: 78. [Crossref]

4. Wilkins T, Sequoia J (2017) Probiotics for gastrointestinal conditions: A summary of the evidence. Am Fam Physician 96: 170-178. [Crossref]

5. Armstrong C (2011) AAP reports on use of probiotics and prebiotics in children $A m$ Fam Physician 83: 849.

6. Joint $\mathrm{FAO} / \mathrm{WHO}$ Working group on drafting guidelines for the evaluation of probiotics in food (2002) Guidelines for the evaluation of probiotics in food: report of a Joint FAO/WHO Working Group on Drafting Guidelines for the Evaluation of Probiotics in Food, London, Ontario, Canada, April 30 and May 1, 2002. Accessed on 2 April 2019 http://www.who.int/foodsafety/publications/fs_management/probiotics $2 /$ en/index.html

7. Thomas DW, Greer FR, American academy of pediatrics committee on nutrition, American academy of pediatrics section on gastroenterology, hepatology, and nutrition (2010) Probiotics and prebiotics in pediatrics. Pediatrics 126: 1217-1231. [Crossref]

8. Braegger C, Chmielewska A, Decsi T, Kolacek S, Mihatsch W, et al. (2011) Supplementation of infant formula with probiotics and/or prebiotics: a systematic review and comment by the ESPGHAN committee on nutrition. J Pediatr Gastroenterol Nutr 52: 238-250. [Crossref]

9. Al-Azri H, Ratnapalan S (2014) Case-based learning in continuing medical education review of randomized controlled trials. Can Fam Physician 60: 157-165. [Crossref]

10. Marinopoulos SS, Baumann MH (2009) Effectiveness of continuing medical education American college of chest physicians evidence-based educational guidelines. Chest 135: $17 \mathrm{~S}-28 \mathrm{~S}$.

11. Ahmed K, Wang TT, Ashrafian H, Layer GT, Darzi A, et al. (2013) The effectiveness of continuing medical education for specialist recertification. Can Urol Assoc J 7: 266272. [Crossref]

12. Wang H, Li N, Zhu H, Xu S, Lu H, et al. (2013) Prescription pattern and its influencing factors in Chinese county hospitals: a retrospective cross-sectional study. Plos One 8: e63225. [Crossref]

13. Kun Y, Jianwen C, Hua F, Huifen C, Yizhong Z (2002) Analysis of factors affecting physicians' prescribing conduct. Chin J Hosp Admin 18: 92-94.

14. Murshid MA, Mohaidin Z (2017) Models and theories of prescribing decisions: A review and suggested a new model. Pharm Pract (Granada) 15: 990. [Crossref]

15. Godin G, Bélanger-Gravel A, Eccles M, Grimshaw J (2008) Healthcare professionals' intentions and behaviours: A systematic review of studies based on social cognitive theories. Implement Sci 3: 36. [Crossref]

16. Légaré F, Borduas F, Freitas A, Jacques A, Godin G, et al. (2014) Development of a simple 12-item theory-based instrument to assess the impact of continuing professional development on clinical behavioral intentions. PLoS One 9: e91013. [Crossref]

17. Schrader PG, Lawless KA (2004) The knowledge, attitudes \& behaviors approach ow to evaluate performance learning in complex environments. Performance Improvement 43: $8-15$

18. Piovani D, Clavenna A, Cartabia M, Bortolotti A, Fortino I, et al. (2017) Assessing the quality of paediatric antibiotic prescribing by community paediatricians: A database analysis of prescribing in Lombardy. BMJ Paediatr Open 1. [Crossref]

19. Teeling-Smith G (1968) Use and abuse of advertising in medicine. Advertising and the pattern of prescribing. Proc R Soc Med 61: 748-750. [Crossref]

20. Jain S, Upadhyaya P, Goyal J, Kumar A, Jain P, et al. (2015) A systematic review of prescription pattern monitoring studies and their effectiveness in promoting rational use of medicines. Perspect Clin Res 6: 86. [Crossref]

21. Ivanovska V, Hek K, Mantel Teeuwisse AK, Leufkens HG, Nielen MM, et al. (2016) Antibiotic prescribing for children in primary care and adherence to treatment guidelines. J Antimicrob Chemother 71: 1707-1714. [Crossref]

22. Trotta F, Mayer F, Mecozzi A, Amato L, Addis A (2017) Impact of guidance on the prescription patterns of G-CSFs for the prevention of febrile neutropenia following anticancer chemotherapy: a population-based utilization study in the Lazio Region. BioDrugs 31: 117-124. [Crossref]

23. Adams J (2011) Nurse prescribing ethics and medical marketing. Nursing Stand 25 62-67. [Crossref]

24. King M, Bearman PS (2017) Gifts and influence: Conflict of interest policies and prescribing of psychotropic medications in the United States. Soc Sci Med 172: 153162. [Crossref] 
Basrowi RW (2019) Factors influencing probiotics recommendation among pediatricians in Indonesia

25. Coleman J, Katz E, Menzel H (1957) The diffusion of an innovation among physicians. Sociometry 20: 253-270.
26. Majid D, Elahe K, Bereket MT (2018) Factors influencing decision of physicians: A review. Ethiop J Sci 28: 795. [Crossref]

Copyright: $(02019$ Basrowi RW. This is an open-access article distributed under the terms of the Creative Commons Attribution License, which permits unrestricted use, distribution, and reproduction in any medium, provided the original author and source are credited. 